\title{
Modeling and Simulation of an Emulator of Photovoltaic Generator
}

\author{
Mustapha Elyaqouti \\ ERTIAER, EST Agadir, Ibn \\ Zohr University, Agadir, \\ Morroco
}

\author{
Lahoussine Bouhouch \\ ERTIAER, EST Agadir, Ibn \\ Zohr University, Agadir, \\ Morroco
}

\author{
Ahmed Ihlal \\ LMER, FS Agadir, BP 8106, \\ Ibn Zohr University, Agadir, \\ Morroco
}

\begin{abstract}
In this paper, we suggest and simulate a model of an electronic device emulating the electric behavior of a photovoltaic generator. This emulator can power an electric installation under study, to adjust it and/or test it. The proposed model is composed on a buck converter controlled by a $P W M$ signal (Pulse Width Modulation). This emulator reproduces perfectly the behavior of the photovoltaic panel Kyocera-KC40 used in the ERTAIER laboratory (Research team in advanced technologies and renewable energy engineering).
\end{abstract}

\section{General Terms}

Emulator of photovoltaic generator

\section{Keywords}

Photovoltaic panel; Photovoltaic emulator; Buck converter; Signal PWM

\section{INTRODUCTION}

Photovoltaic solar energy is the result of direct conversion of photonic energy carried by sun rays by means of solar cells called photovoltaic $(P V)$ cells, manufactured with materials that are sensitive to visible wavelength. The combination of many $P V$ cells in series/parallel gives a photovoltaic generator $(P V G)$, with a nonlinear static characteristics current-voltage $I(V)$ [1]. This $P V G$ produces the electric energy in DC form [2].

The electrical energy produced by a PV system is highly dependent on random and uncontrollable meteorological conditions. Therefore, the use of an actual PV system for research investigations concerning problems with power management as the MPPT testing, interfacing the PV generator to the grid and the load is difficult and sometimes impossible. Hence, there is a need to seek other alternative solutions to this problem [3à5]. One of these solutions is the creation of artificial metrological conditions inside the laboratory using appropriate lamps which have a spectrum reproducing natural light (solar simulator). This solution poses some problems related to the consumption of a significant power and heat generation [6].

The most appropriate solution is the use of a photovoltaic generator emulator (EGPV). This is a device which has current-voltage output characteristics similar to that of a PV generator. The emulator can replace the PV generator in an installation so as to study, to adjust or test it. Three types of solutions are possible for the realization of an EGPV [7]:

The first solution is based on the equivalent diagram of the PV generator. It consists of a realization of a power device reconstituting the equivalent diagram of the PV generator from the power electronics elements like sources, resistors and diodes. The realization of such device is simple but it has several drawbacks, such as low performance, due to the power dissipated in the parallel on the output diodes which requires efficient cooling system, and parasitic behavior difficult to offset related to discrete elements used.

The second solution is based on the amplification of an elementary cell. It is to amplify the actual characteristic of an elementary cell in setting the right conditions of light and temperature at the heart of a linear current amplifier and voltage adjustable gains.

Finally, the third solution is to provide a programmable power supply. This is the most practical solution, this one is to provide a power source to feature programmable output similar to that of a PV array. It offers a great flexibility and a very good performance. Thus, we have adopted the last solution for the realization of our PV emulator.

The organization of this paper is as follows: first a brief introduction is given, and then in section 2 , we present the measurement bench that serves to determine the I-V characteristics of the KYOCERA-KC40 photovoltaic module. The section 3 shows the modeling of our emulator. In the last section, the simulation results are shown and followed by a conclusion.

\section{MEASUREMENT BENCH}

In ERTAIER laboratory of Superior School of Technology in Agadir (ESTA), we dispose of a Kyocera-KC40 [8] type $P V$ panel (Fig. 1). This panel is constituted of 36 polycrystalline cells able to produce a $40 \mathrm{~W}$ peak power in standard testing conditions (irradiance: $1000 \mathrm{~W} / \mathrm{m}^{2}$, temperature: $25^{\circ} \mathrm{C}$ and AM 1.5 spectrum). Meteorological data, such as solar radiation, ambient temperature, etc., are collected through the different sensors of the meteorological station equipped with an acquisition unit Campbell type CRX10 (Fig. 1) [9].
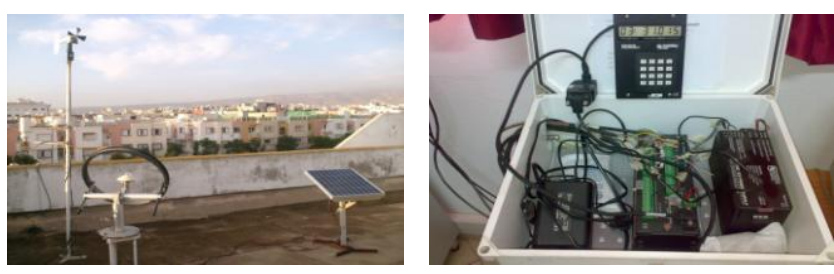

Fig. 1. The Kyocera-KC40 photovoltaic panel and metrological station CRX10 acquisition unit

In order to measure the delivered voltages and currents by PV panel in real functioning condition, we use the method of load variation (Fig. 2). 

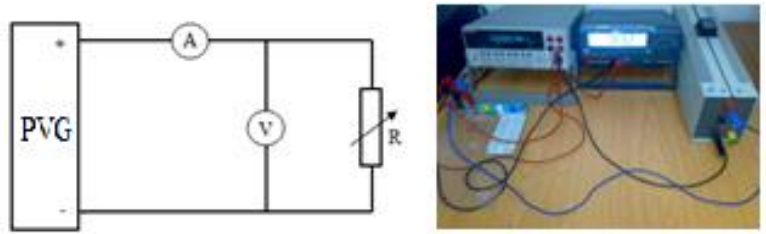

Fig. 2. Measurement setup to $P V G$ characteristics, with the load variation method

The current-voltage $I-V$ output's characteristics of our module are presented in "Fig. 3", for four values of radiation $G$ respectively $920,904,684$ and $230 \mathrm{~W} / \mathrm{m}^{2}$ corresponding to temperatures respectively $27.2,30.6,38.3$ and $36.6^{\circ} \mathrm{C}$.

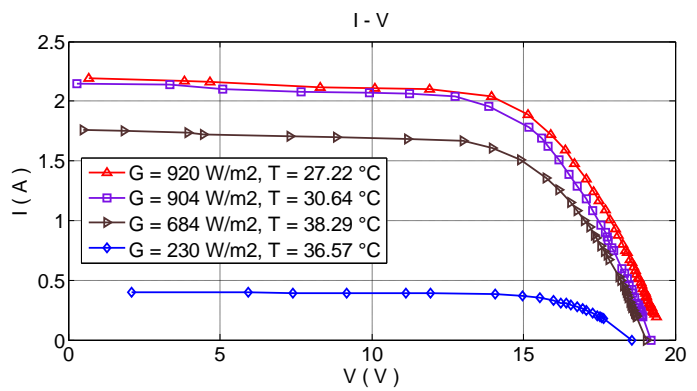

Fig. 3. The characteristics I-V of the KYOCERA-KC40 PV module

\section{MODELING}

In this paragraph, we present the adopted technique to model the emulator that reproduce the physical behavior of a $P V G$. This emulator will have an output characteristic, equivalent to that of the $P V$ panel (Kyocera-KC40) under study with a similar characteristic presented in figure 3.

The synoptic diagram of our presented photovoltaic emulator on figure 4 has been inspired from previous works [7]. It's constituted of:

A buck converter allowing an output voltage varying between 0 and $V_{O C}[10]$.

A control circuit generating the $P W M$ signal, controlling the buck converter.

A digital memory recording the $I-V$ characteristics of our PV panel in case of the studied irradiances.

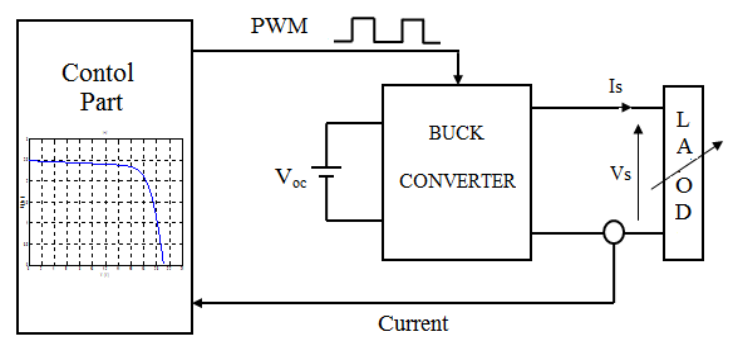

Fig. 4. Synoptic diagram of the $P V G$ emulator

Figure 4 describes the system operating principle: A DC generator $V_{O C}$ supplies an adjustable voltage source which is a buck converter in our case. According to output current value $I s$, the control circuit generates a signal $P W M$, whose duty cycle forces the buck converter to obtain a corresponding output voltage $V s$.

\subsection{Modeling and simulation of the buck converter}

The chosen adjustable voltage source is a buck converter, based on MOSFET transistor. It's inserted between the voltage generator $V_{O C}$ and a resistive load $R$. The inductance $L$ and capacitor $C$ values, will be defined in section 4 . The functioning is at a fixed commutation frequency $f=1 / T$, where $T$ is the transistor commutation period. The electrical circuit equivalent to this buck converter is shown in figure 5 .

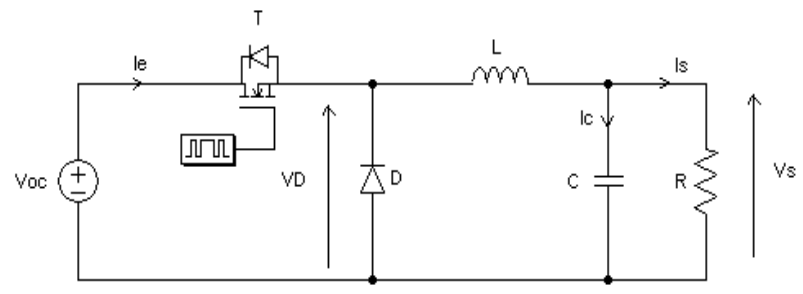

Fig. 5. Electrical circuit equivalent to the buck converter

In the case of a fixed commutation frequency $f$, the Thevenin theorem gives the simplified equivalent circuit of our buck converter, as shown in figure 6 . This simplified scheme will be used to perform modeling.

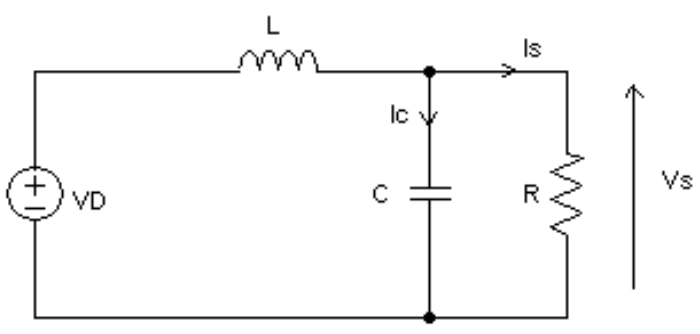

Fig. 6. Simplified electrical scheme of equivalent circuit of the buck converter [11]

The application of Kirchhoff's laws to the equivalent circuit of figure 6 , gives the linear differential equation of second order (1):

$$
L C \frac{d^{2} V s}{d t^{2}}+\frac{L}{R} \frac{d V s}{d t}+V s=V_{D}
$$

This equation corresponds to the transfer function represented by the following expression (2):

$$
\frac{V s}{V_{D}}=\frac{1}{1+\left(\frac{L}{R}\right) p+L C p^{2}}
$$

With $p=j \omega=j 2 \pi f$.

This theoretical analysis leads to figure 7 which represent the block diagram of the studied buck converter under Matlab Simulink. The PWM control block is a block that generates the PWM signal and $\mathrm{R}$ is the load. The two low pass filters (filter and filter1) allowing to filter the current and the output voltage. The detailed diagram of the chopper is shown in Figure 7-b. 
(a)

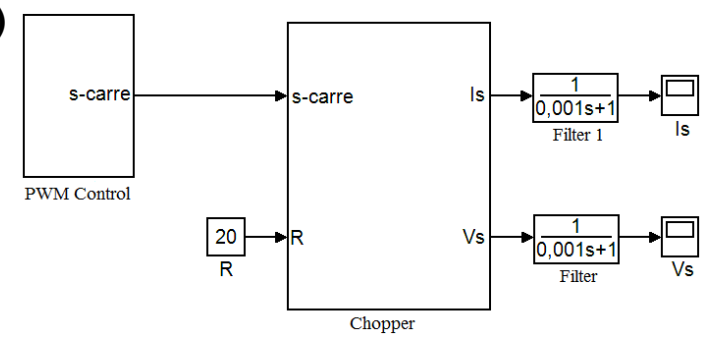

(b)

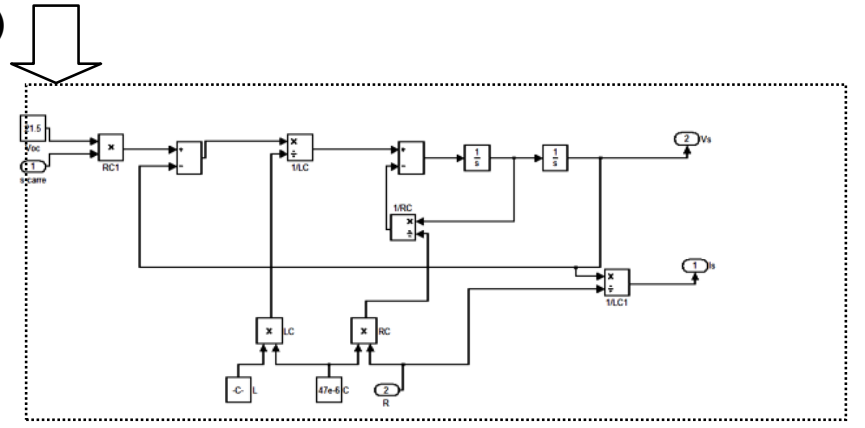

Fig. 7. a) Block diagram of the buck converter in MatlabSimulink b) Detailed diagram of the chopper in

\section{Matlab/Simulink}

\subsection{Control by the PWM signal}

The control by the $P W M$ signal consist to choose a commutation frequency of the MOSFET (T). It also fix, within of the switching period, the intervals conductions of transistor, according to the reference signal $V_{\text {ref }}$ corresponding to the potential of the desired output voltage $V_{S}$. The following figure shows the principle to generate the $P W M$ signal.

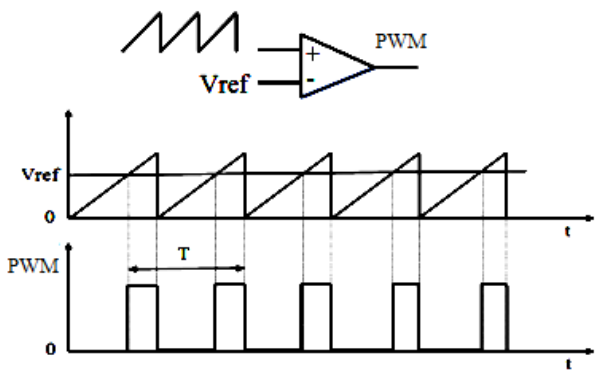

Fig. 8. Principle of generating a $P W M$ signal

The shown comparator in figure 8 generates at its output, a square signal with modulated width pulse ( $P W M$ signal). This is the result of comparing between the output signal $V_{\text {ref }}$ recorded in memory and that produced by a saw tooth generator fixed frequency. This allows to model the control $P W M$ under Matlab/Simulink in the following way (see Fig. 9-a). The $I-V$ characteristics of our $P V$ panel is recorded in memory block detailed in Figure 9-b.

\subsection{Global scheme of PV emulator under Matlab/Simulink}

The study of the various constituent parts of our $P V$ emulator, leads us to overall scheme for simulation under Matlab/Simulink that the figure 10 shown.
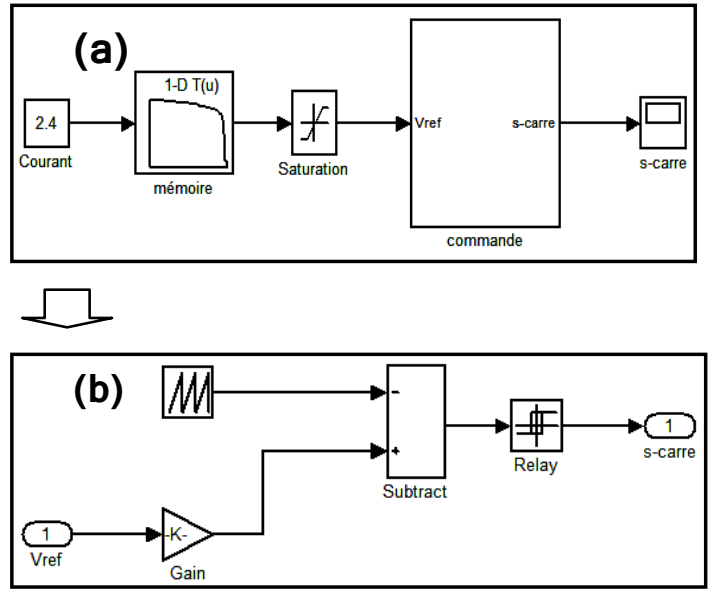

Fig. 9. a) Global Model of $P W M$ control and b) detailed scheme of the control block in Matlab/Simulink

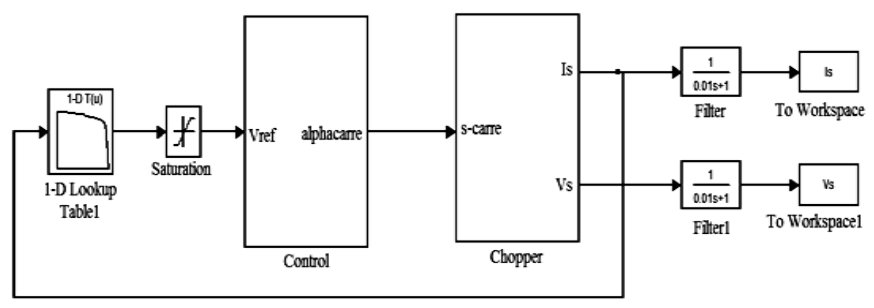

Fig. 10. Global simulation scheme of the $P V$ emulator under Matlab / Simulink

In this global diagram, there are two low pass filters (filter and filter 1 ) allowing to filter the current and the output voltage. The other two blocks named "To workspace" and "To workspace1" are used to transfer the simulation results to the Matlab workspace.

\section{SIMULATION RESULTS}

To illustrate the obtained simulation results for our buck converter, the bellow assumptions are considered:

Commutation frequency: $f=1 / T=20 \mathrm{kHz}$;

Input voltage: $V_{o c}=21.5 \mathrm{~V}$;

Filter parameters: $L=2.08 \mathrm{mH}, C=47 \mu \mathrm{F}$;

The MOSFET (T) and diode (D) are considered ideals.

The figures 11 and 12 summarize the obtained simulation results for the voltage and output current, for various load resistances of the developed $P V$ emulator.

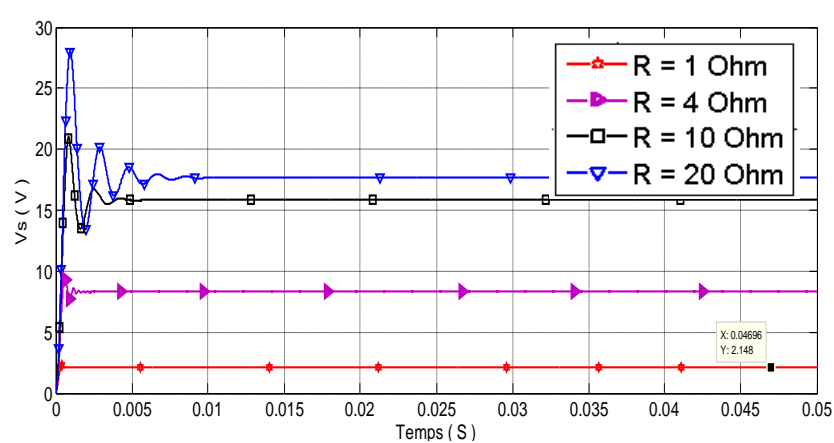

Fig. 11. Output voltage $V_{s}$ for various load resistors values 


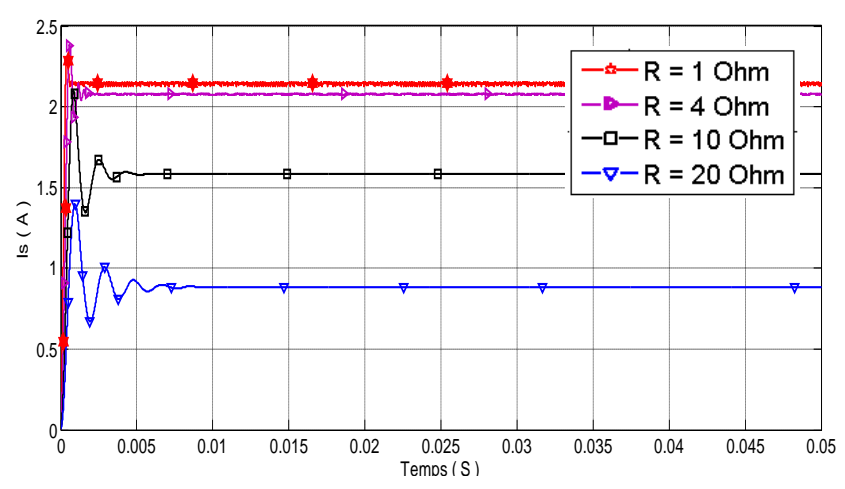

Fig. 12. Output current $I_{s}$ for various load resistors values

According to the simulation results as shown in figures 11 and 12 , we note that the transient doesn't exceed more than $5 \mathrm{~ms}$ for high load resistance, while they are absents for low load resistance.

According to our obtained results, we show that the designed emulator PV has an output characteristic similar to that of the photovoltaic panel Kyocera-KC40 under test.

\section{CONCLUSION}

In this paper, we modeled and simulated a $P V$ emulator replicating the electrical behavior of photovoltaic panel Kyocera-KC40 of the ERTAIER laboratory. Simulation results show that the modeling of the designed $P V$ emulator, gives a characteristic $I(V)$ similar to that measured at the $P V$ generator output available. it has also been shown that the output transient's current and voltage does not exceed more than $5 \mathrm{~ms}$.

The perspectives of this work are to develop a prototype of this emulator that can be used for educational purposes and research investigations.

\section{REFERENCES}

[1] Angel Cid Pastor. 2006, Conception et réalisation de modules photovoltaïques électronique, $\mathrm{PhD}$ thesis, Institut National des Sciences Appliquées de Toulouse, France.

[2] Long Bun. 2006. Détection et Localisation de Défauts pour un Système PV, PhD thesis, Grenoble University, France.
[3] Ahmed F. Ebrahim, S.M.W. Ahmed, S.E. Elmasry, Osama A. Mohammed. 2015. Implementation of a PV emulator using programmable DC power supply, Proceedings of the IEEE SoutheastCon, Fort Lauderale, Florida, April 9-12, 2015.

[4] Javier Chavarria, Domingo Biel, Francesc Guinjoan, Alberto Poveda. 2014. FPGA-based design of a step-up photovoltaic array emulator for the test of PV gridconnected inverters", IEEE 23 rd International Symposium on Industrial Electronics (ISIE).

[5] Yunus Erkya, Paul Moses, Isaac Flory, Sylvain Marsillac. 2015. Development of a solar photovoltaic module emulator, IEEE 42nd photovoltaic Specialist Conference (PVSC).

[6] Maria Carmela Di Piazza, Gian Paolo Vitale. 2013. Photovoltaic sources: Modeling and Emulation", Green Energy and Technology.

[7] Ludovic Protin, Stéphan Astier, "Convertisseurs photovoltaic", Techniques de l'ingénieur, Doc 3360, pp. 13-15.

[8] http://www.solarshop-europe.net/solarcomponents/solarmodules/ kyocera_kc-40_m_695.html

[9] Mustapha Elyaqouti, Lahoucine Bouhouch, Ahmed Ihlal, . 2016. Global solar radiation estimation on a horizontal and tilted plane in Agadir city, Morocco", International Journal of Computer Applications Volume 137, No.6, March 2016, pp. 21-24.

[10] Michel Pinard. 2007. Convertisseur et électronique de puissance: Commande, description, mise en œuvre, Dunod, ISBN : 978-2-10-049674-7.

[11] Drif, M., Malek, A., Krim, F. 1998, Nouvelle technique de commande non linéaire d'un convertisseur $\mathrm{cc} / \mathrm{cc}$ pour applications photovoltaïques, Revue des Energies Renouvelables, Vol. 1, No. 2, ISSN 1112-2242, pp. 6577.

[12] Spector, A. Z. 1989. Achieving application requirements. In Distributed Systems, S. Mullender 